\title{
DEGRADAÇÃO DA MATÉRIA ORGÂNICA DA VINHAÇA UTILIZANDO O COAGULANTE NATURAL TANINO
}

Vitor Amigo Vive ${ }^{1}$, Maria Cristina Rizk ${ }^{2}$

${ }^{1}$ Discente em Engenharia Ambiental pela Universidade Estadual Paulista - UNESP - Presidente Prudente. * Bolsista FAPESP. ${ }^{2}$ Docente da Universidade Estadual Paulista - UNESP - Presidente Prudente. E-mail: : vitorvive@ hotmail.com

\section{RESUMO}

A geração de vinhaça, principal efluente das destilarias de álcool, é bastante significativa, uma vez que são produzidos aproximadamente 13 litros da mesma por litro de álcool destilado. Devido ao seu caráter poluente, a vinhaça se disposta de forma inadequada, pode prejudicar as propriedades físicas e químicas do solo e contaminar os recursos hídricos superficiais e subterrâneos. 0 presente trabalho objetivou a remoção dos sólidos presentes na vinhaça por meio do processo de coagulação/floculação/sedimentação, utilizando o coagulante natural tanino. Os ensaios foram realizados em jar-test na temperatura aproximada de $25^{\circ} \mathrm{C}$, com amostras de $200 \mathrm{~mL}$ de vinhaça e a variação da concentração de coagulante. As amostras foram submetidas à mistura rápida por 1 minuto (100rpm), seguida de mistura lenta por 30 minutos (50rpm) e repouso para sedimentação de 24 horas. Os resultados mostraram que o tanino removeu cerca de $37 \%$ da DQO da vinhaça. Palavras-chave: Vinhaça, coagulação/floculação/sedimentação, tanino, DQO.

\section{INTRODUÇÃO E OBJETIVO}

Nos últimos tempos, as áreas de produção de cana-de-açúcar (Saccharum sp.) vêm aumentando continuamente, sobretudo na região Centro-Oeste do Brasil. Concomitante ao aumento da produção de álcool, ocorre a produção de vinhaça, efluente denso produzido a partir de processos de destilação do álcool, de cor escura, com carga orgânica elevada e pH ácido (ZAYAS et al., 2007).

Geralmente, o teor de matéria orgânica da vinhaça é equivalente a uma demanda biológica de oxigênio $\left(\mathrm{DBO}_{5}\right)$ na ordem de 25.000 a $45.000 \mathrm{mg} \cdot \mathrm{L}^{-1}$ e uma demanda química de oxigênio (DQO) de 70.000 a 120.000 mg.L ${ }^{-1}$ (LEAL et al., 2003). Como consequência, a vinhaça tem um poder altamente poluente e, considerando-se que a produção de 1 tonelada de álcool anidro gera $16 \mathrm{~m}^{3}$ de vinhaça, em média, a eliminação da vinhaça representa um passivo ambiental grave (VLYSSIDES et al., 1997).

Segundo Freire e Cortez (2000), o poder poluente da vinhaça é cerca de cem vezes maior que o do esgoto doméstico justamente em decorrência da sua riqueza em matéria orgânica, sólidos dissolvidos, sólidos suspensos e baixo $\mathrm{pH}$, onde os valores elevados destes parâmetros são suficientes para considerar a vinhaça altamente nociva à fauna e à flora. 
O sistema de tratamento físico-químico de coagulação/floculação/sedimentação com coagulantes naturais vem sendo estudado no tratamento de diferentes tipos de efluentes, podendo assim ser empregado no tratamento da vinhaça. Vários estudos utilizando o tanino vegetal têm mostrado que este coagulante possui propriedades efetivas e não tóxicas aos seres humanos e animais (MORAES et al. 2007; NAGASHIMA, 2009; VANACÔR E GEHLING, 2007).

$\mathrm{O}$ tanino é um coagulante vegetal efetivo numa ampla faixa de $\mathrm{pH}$, que elimina o uso de alcalinizantes (como soda ou cal), não acrescenta metais ao processo e proporciona uma redução no volume de lodo a ser descartado. Ainda, devido a sua composição orgânica, pode ser biologicamente degradado ou eliminado termicamente (ÖZACAR e SENGIL, 2003; SILVA et al.; 2004).

Neste contexto, este estudo tem por objetivo investigar o emprego de coagulação/floculação/sedimentação com o coagulante natural tanino, visando à remoção de DQO.

\section{METODOLOGIA}

O efluente utilizado neste trabalho foi coletado numa Usina de Açúcar e Álcool do oeste paulista, no período da safra de cana-de-açúcar (março de 2013). As amostras foram armazenadas em galões de 5 litros e conservadas a temperatura abaixo de $10^{\circ} \mathrm{C}$ até o seu uso.

A DQO foi determinada de acordo com a metodologia do "Standard Methods" (APHA, 1998). O método baseia-se na oxidação da matéria orgânica por 2 horas de aquecimento em presença de meio ácido $\left(\mathrm{H}_{2} \mathrm{SO}_{4}\right)$ e dicromato de potássio $\left(\mathrm{K}_{2} \mathrm{Cr}_{2} \mathrm{O}_{7}\right)$.

Utilizou-se como digestor um reator da marca HANNA e para leitura espectrofotométrica um espectrofotômetro HACH - modelo DR3900, no qual foi inserida uma curva padrão para os reagentes preparados no método. As determinações das concentrações de DQO nas amostras foram realizadas em duplicatas, utilizando o valor médio.

A determinação do $\mathrm{pH}$ foi feita com a utilização de um potenciômetro e eletrodos (pHmetro). As medidas de $\mathrm{pH}$ foram realizadas no pHmetro da marca HANNA - modelo HI 221, segundo a metodologia descrita no manual do aparelho.

Os ensaios de coagulação/floculação/sedimentação ocorreram em aparelho jar-test simples de seis provas, com regulador de rotação das hastes misturadoras, em temperatura ambiente. 
Nos ensaios, era utilizado um volume de $200 \mathrm{~mL}$ de vinhaça in natura, ao qual eram adicionadas diferentes concentrações do coagulante tanino vegetal. Foram preparadas soluções de tanino a $10 \%(\mathrm{v} / \mathrm{v})$. A partir da adição do coagulante, as amostras foram sujeitas à agitação rápida por 1 minuto (mistura rápida 100 rpm) e à agitação lenta por 30 minutos (mistura lenta 50 rpm).

Foram realizados 24 ensaios de coagulação/floculação/sedimentação (12 condições distintas e suas repetições), variando-se a concentração de coagulante tanino (25, 50 e $100 \mathrm{~mL} / \mathrm{L})$ e a faixa de $\mathrm{pH}(4,0 ; 5,0 ; 6,0$ e 7,0). Todos os tratamentos foram avaliados em termos da eficiência de remoção de DQO. As variáveis de resposta foram lidas em duplicata.

O ajuste de pH foi feito com solução de ácido clorídrico $25 \%$ e de solução de hidróxido de sódio $50 \%$.

Após a coagulação/floculação, as amostras permaneceram em repouso por um período de 24 horas, para sedimentação dos flocos formados. O sobrenadante foi analisado em termos de DQO.

\section{RESULTADOS}

Antes de cada ensaio foram determinados os valores de DQO e pH do efluente. A Tabela 1 apresenta as variações encontradas para cada parâmetro analisado.

Tabela 1. Variações dos parâmetros físico-químicos no efluente bruto

\begin{tabular}{cc}
\hline Parâmetro & Variação dos valores \\
\hline $\mathrm{pH}$ & 4,65 a 4,80 \\
$\mathrm{DQO}\left(\mathrm{mg} \mathrm{O}_{2} \cdot \mathrm{L}^{-1}\right)$ & 11.105 a 16.734 \\
\hline
\end{tabular}

A Figura 1 apresenta os resultados de remoção de DQO em todas as faixas de pH testadas para as respectivas concentrações de coagulante tanino. 


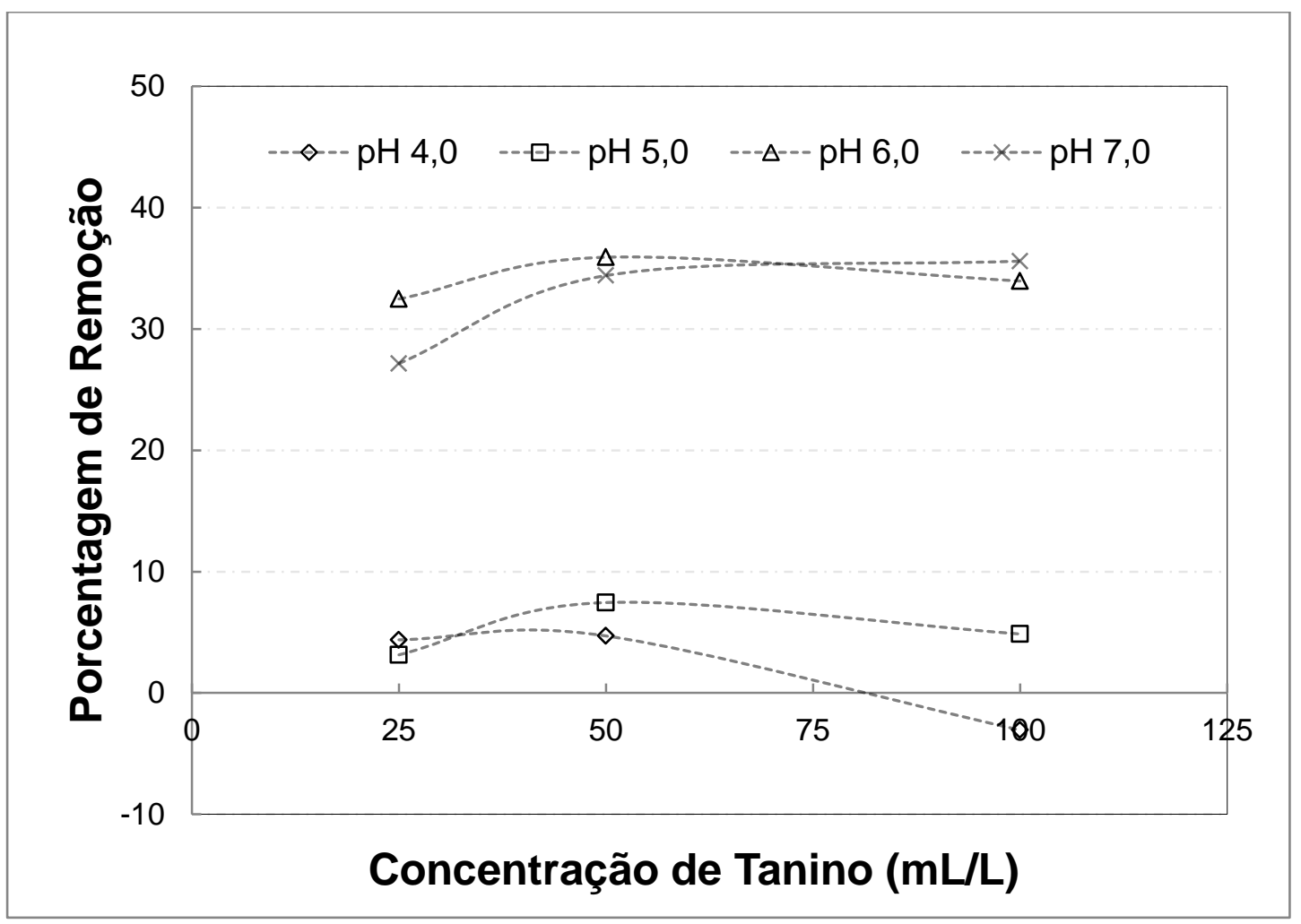

Figura 1. Remoções de DQO nos ensaios de coagulação/floculação

\section{DISCUSSÃO}

A partir dos resultados apresentados na Tabela 1 é possível verificar a elevada concentração de DQO, o que dificulta o tratamento da vinhaça.

Analisando a Figura 1 pode-se perceber uma diferença considerável entre os resultados dos ensaios em pH 4,0 e 5,0 com os resultados dos ensaios em pH 6,0 e 7,0. A remoção de $\mathrm{DQO}$ no $\mathrm{pH}$ 4,0 apresentou nas concentrações de 25 e $50 \mathrm{~mL} / \mathrm{L}$ de tanino aproximadamente 4 e $5 \%$ de remoção, respectivamente. Na concentração de $100 \mathrm{~mL} / \mathrm{L}$ houve um aumento de DQO em torno de 3\%. Da mesma forma, a remoção de DQO no pH 5,0 apresentou resultados próximos de aproximadamente 7; 5 e 3\% para as respectivas concentrações de 50, 100 e 25 mL/L.

No entanto, para as faixas de pH 6,0 e 7,0 os resultados foram melhores. Para a remoção de $\mathrm{DQO}$ no pH 6,0 o melhor resultado foi alcançado na concentração de $50 \mathrm{~mL} / \mathrm{L}$ de coagulante tanino com aproximadamente $36 \%$. O segundo melhor resultado ocorreu na concentração de 100 $\mathrm{mL} / \mathrm{L}$ com cerca de $34 \%$, seguindo da concentração de $25 \mathrm{~mL} / \mathrm{L}$ com $32 \%$. Na remoção de DQO no pH 7,0 o melhor resultado foi apresentado na concentração de $100 \mathrm{~mL} / \mathrm{L}$ de coagulante tanino com aproximadamente $36 \%$. O segundo melhor resultado ocorreu na concentração de $50 \mathrm{~mL} / \mathrm{L}$ com cerca de $34 \%$, seguido da concentração de $25 \mathrm{~mL} / \mathrm{L}$ com $27 \%$. 
Assim, os resultados de remoção de DQO obtidos neste trabalho aumentaram à medida que o $\mathrm{pH}$ tornou-se mais próximo da neutralidade. A porcentagem de remoção de DQO variou de 27 a $36 \%$ na faixa de $\mathrm{pH}$ de 6,0 a 7,0. Entre os valores de pH 4,0 e 5,0 a porcentagem de remoção de DQO diminuiu, variando de -3\% (acréscimo percentual) a 7\%.

Segundo Di Bernardo et al. (2002), este fenômeno pode ser explicado pelo fato que as interações entre as partículas coloidais presentes no efluente com as moléculas de coagulante ocorreram de forma mais acentuada nas faixas de $\mathrm{pH}$ próximas da neutralidade, pois as forças de repulsão, isto é, o potencial Zeta, decaiu e possibilitou a aglomeração de flocos aumentando a eficiência do processo de coagulação/floculação.

\section{CONCLUSÃO}

De acordo com os resultados deste trabalho pode-se dizer o processo de coagulação/floculação/sedimentação foi menos eficiente nas faixas de $\mathrm{pH}$ mais ácidas, onde a remoção de DQO foi inferior quando comparado com os resultados das faixas de $\mathrm{pH}$ mais próximas da neutralidade.

No pH 6,0 a maior remoção foi de aproximadamente $36 \%$ na concentração de $50 \mathrm{~mL} / \mathrm{L}$ de coagulante tanino. No $\mathrm{pH} \mathrm{7,0} \mathrm{o} \mathrm{melhor} \mathrm{resultado} \mathrm{foi} \mathrm{alcançado} \mathrm{na} \mathrm{concentração} \mathrm{de} 100 \mathrm{~mL} / \mathrm{L}$ de coagulante tanino com cerca de $36 \%$ de remoção.

\section{REFERÊNCIAS}

APHA - American Public Health Association. Standard methods for the examination of water and wastewater. Washington D.C., 20th ed, 1998.

DI BERNARDO, L.; DI BERNARDO, A.; CENTURIONE FILHO, P. L. Ensaios de tratabilidade de água e dos resíduos gerados em estações de tratamento de água. 1ํ ed. São Carlos: Rima, 2002, p. 237.

FREIRE, W. J.; CORTEZ, L. A. B. Vinhaça de cana-de-açúcar. Guaíba: Agropecuária, 2000. 203p.

LEAL, G. I.; CHIRINOS, E.; LEAL, M.; MORÁN, H. Characterization physicochemical of vinasse of Agave cocui and your possible use agroindustrial. Multiciencias, v. 3, p. 83-88, 2003.

MORAES, L. C. K; BERGAMASCO, R.; TAVARES, C. R. G; HENNIG, D.; BONGIOVANI, M.C. Avaliação da eficiência de remoção de cor e turbidez, utilizando como agente coagulante os taninos vegetais, com a finalidade de obtenção de água tratada. In: 240 Congresso Brasileiro de Engenharia Sanitária e Ambiental, 2007, Belo Horizonte, MG.

NAGASHIMA, L. A. Monitoramento do Lixiviado em Lagoa de Estabilização e Estudo da Aplicabilidade do Reagente Fenton e do Coagulante Vegetal Tanino como Formas de 
Tratamento. Tese de Doutorado - Programa de Pós-Graduação em Engenharia Química, Universidade Estadual de Maringá, Maringá, PR, 2009.

ÖZACAR, M.; SENGIL, I. A. Evaluation of tannin biopolymer as a coagulant aid for coagulation of colloidal particles. Colloids and Surfaces A: Physicochem. Eng. Aspects, v. 229; p. 85-96, 2003. http://dx.doi.org/10.1016/i.colsurfa.2003.07.006

SILVA, J.; GOMES, L.P.; DECUSATI, O.; LAMB, L.H. Aplicação de floculante vegetal no tratamento de águas. IV Simpósio Internacional de Qualidade Ambiental, Porto Alegre, RS, 2004.

VANACÔR, R. N.; GEHLING, G. R. Caracterização do lodo dos decantadores de uma ETA convencional utilizando coagulante orgânico derivado do tanino. In: 24ํ Congresso Brasileiro de Engenharia Sanitária e Ambiental, 2007, Belo Horizonte.

VLYSSIDES, A.G.; ISRAILIDES, C.J.; LOIZIDOU, M. Electrochemical treatment of vinasse from beet molasses. Water Sciency Technology, v. 36, n. 2-3, p. 271-278, 1997. http://dx.doi.org/10.1016/S0273-1223(97)00398-3

ZAYAS, T.; RÓMERO, V.; SALGADO, L.; MERAZ, M.; MORALES, U. Applicability of coagulation/flocculation and electrochemical processes to the purification of biologically treated vinasse effluent. Separation and Purification Technology, v. 57, p. 270-276, 2007. http://dx.doi.org/10.1016/j.seppur.2007.04.019

\section{AGRADECIMENTOS}

Os autores agradecem a Fundação de Amparo à Pesquisa do Estado de São Paulo pelo apoio financeiro. 